\begin{tabular}{|c|c|c|c|c|}
\hline \multicolumn{5}{|c|}{ ESTIMATED HG EMISSIONS FROM FOREST BURNING IN THE AMAZON } \\
\hline Biomass & $\mathrm{tha}^{-1}$ & $\mathrm{Hg}\left(\mu \mathrm{g} \mathrm{g}^{-1}\right)$ & $\begin{array}{l}\mathrm{Hg} \text { release } \\
\text { efficiency }(\%)\end{array}$ & $\begin{array}{l}\text { Hg release } \\
\text { (g per ha) }\end{array}$ \\
\hline $\begin{array}{l}\text { Above ground wood and litter } \\
\text { (roots, fallen trunks and } \\
\text { standing trunks) }\end{array}$ & 216 & 0.02 & 90 & 3.8 \\
\hline $\begin{array}{l}\text { Above ground leaves and below } \\
\text { ground roots }\end{array}$ & 54 & 0.03 & 75 & 1.2 \\
\hline Soil organic matter & 47 & 0.30 & 20 & 2.8 \\
\hline Total & 317 & & & 7.8 \\
\hline
\end{tabular}

cient help of mycorhizae. Plant litter in the Amazon shows lower concentrations than the living leaves ${ }^{10}$. Therefore I will use the same concentrations used for trunks for this compartment. The soil organic matter $\mathrm{Hg}$ content used by Veiga et al. is in agreement with reported values for the Amazon, and their value for efficiency of $\mathrm{Hg}$ release during burning seems fair.

Recalculating the estimates of $\mathrm{Hg}$ release to the Amazon atmosphere through forest burning (see table) and using the deforestation rates of 1990-1991 of $11,100 \mathrm{~km}^{2}$, I obtain approximately $8.7 \mathrm{t}$ for this year. Even taking the largest estimates of $1978-1988$, roughly $17 \mathrm{t}$ of $\mathrm{Hg}$ would have been emitted annually during that period, still four to five times lower than the proposed estimate of Veiga et al. Even this value is likely to be an overestimate, as $\mathrm{Hg}$ concentrations in biomass from the Amazon forest as well as in soil organic matter will probably be much lower. In addition, many deforested areas are now in various stages of regrowth following abandonment, therefore actually accumulating $\mathrm{Hg}$ in their fast-growing bio-

\title{
Origin of chondrules explained
}

SIR - Chondrules generally are millimetre-sized, near-spherical stony objects that are the main constituent of the most primitive types of meteorite. Many regard chondrules as having formed in a protoplanetary disk by complete or partial melting of nebular solids. In contrast, I believe that chondrules probably resulted from interactions between already differentiated, partly molten planetary bodies.

My view was, unfortunately, misrepresented in the News and Views by Ash ${ }^{1}$ by his statement that I “. . . prefer an origin in a modified, geologically undifferen tiated planetary body. ...". Since the early 1970 s, when plagioclase glass with a planetary chemical signature was discovered in an ordinary chondrite ${ }^{2}$, I have tried to demonstrate that some chondrules at least

1. Ash, R. Nature 372, 219-220 (1994)

Hutchison, R. \& Graham, A.L. Nature 255, 471 (1975).

3. Hutchison, R., Alexander, C.M.O'D. \& Barber, D.J. Phil. Trans. R. Soc. A325, 445-458 (1988).

4. Palme, H. Chondrules and the Protoplanetary Disk (abstr.) 30 (Lunar Planet. Inst., Houston, 1994). mass. Thus tentative estimates of total $\mathrm{Hg}$ released from deforestation during the past 20 years are useless. Finally, a significant proportion of the biomass remains intact after burning, keeping a fraction of the $\mathrm{Hg}$ preserved as partially burnt vegetation and as coal.

Using the year 1990 for comparison, $\mathrm{Hg}$ emission to the atmosphere in the Brazilian Amazon due to gold mining ranged from 70 to $100 \mathrm{t}$ (refs 2, 3). Recently, this type of mining spread throughout other Amazonian countries. In Venezuela, 40 to $50 \mathrm{t}$ of $\mathrm{Hg}$ are released by this activity ${ }^{3}$. In Colombia, Peru, Ecuador and Guyana, at least 10-20 $\mathrm{t}$ more are released annually ${ }^{2}$, and more mining fields are being opened every year. Therefore, although deforestation is a serious environmental threat to the Amazon, if there is any "significant villain" in the emission of $\mathrm{Hg}$ to the Amazon, it is definitely gold mining.

Luiz Drude de Lacerda

Departamento de Geoquímica,

Universidade Federal Fluminense,

Niterói, Rio de Janeiro 24020-007,

Brazil

were the product of differentiated planetary bodies ${ }^{3}$. Furthermore, Ash perpetuates a common misconception that chondrules have "approximately solar" "relative abundances of refractory trace elements". At the conference on which his article was based, after exchanges between several participants, it was agreed that chondrites (the bulk meteorites) have approximately solar elemental abundances but that there is "large compositional variability of chondrules from a single meteorite, reflected in major variations of $\mathrm{Mg} / \mathrm{Si}$ ratios, of $\mathrm{Al}$ and other refractory element abundances..."4.

The 'magic' to be explained is how chemically diverse objects, chondrules, be they nebular or planetary, when mixed in nature in gram-sized or larger amounts, always produce uniform, near solar compositions.

\section{Robert Hutchison}

Mineralogy Department,

Natural History Museum,

London SW7 5BD, UK

\section{The world's oldest songbird}

SIR - The songbirds or passerines (Passeriformes) are the most speciose and widely distributed order of living birds, comprising about $60 \%$ of the 9,000-10,000 Recent species and occurring on all continents except Antarctica. It is not known whether the Passeriformes had a northern or southern origin. Traditional, pre-continental drift views held that Australo-Papuan passerines were derived from and often confamilial with Northern Hemisphere invaders ${ }^{1}$, an interpretation challenged by palaeontological evidence and molecular studies ${ }^{2}$. These latter studies concluded that the many endemic Australo-Papuan passerines were part of a large-scale autochthonous radiation from but a few ancestral types, overlaid by more recent northern invaders ${ }^{2}$.

These ideas have yet to be verified by unequivocally identified fossils; all purported Eocene and Oligocene passerines before 1989 were misidentified ${ }^{3}$. The earliest undoubted passerines come from Late Oligocene deposits in France ${ }^{4}$. The extensive early Tertiary sites in North America and Europe contain many small arboreal forms, most belonging to the Coraciiformes; none is passerine ${ }^{3}$. It has been proposed that passerines had a southern origin, not spreading to the Northern Hemisphere until the mid-Tertiary'. Unfortunately, there is no evidence of early Tertiary passerines in Southern Hemisphere deposits ${ }^{6,7}$. An Early Eocene site from Murgon, southeastern Queensland, has now yielded material identifiable as passerine.

The matrix yielding the fossils is green clay, radiometrically dated potassium/argon; illite) at $54.6 \pm 0.05 \times 10^{6}$ years $^{8}$. This age is corroborated by non-avian elements of the Tingamarra local fauna, which includes Australia's oldest frog, trionychid turtle, madtsoiid snake, marsupials, bat, and non-volant placental mammal. The fossils of passerine and other birds form the earliest modern, nonmarine avian assemblage from Australia ${ }^{9}$.

\footnotetext{
1. Mayr, E. Bull. Am. Mus. nat. Hist. 93, 123-194 (1944)

2. Sibley, C.G. \& Ahlquist, J.E. Phylogeny and Classification of Birds: A Study in Molecular Evolution (Yale Univ. Press, New Haven, 1990).

3. Olson, S.L. in Avian Biology, Vol. 8 (eds Farner, D.S. et al.) 79-238 (Academic, New York, 1985).

4. Mourer-Chauviré, C. . Hugueney, M., \& Jonet, P. C. r. hebd. Séanc. Acad. Sci., Paris (ser. 2) 309, 843-849 (1989)

5. Olson, S.L. Acta XIX Congr. Int. Om. 2023-2029 (1988).

6. Vickers-Rich, P. in Vertebrate Palaeontology of Australasia (eds Vickers-Rich, P., Baird, R.F., Monaghan, J. \& Rich, T.H.) 722-808 (Nelson, Melbourne, 1991).

7. Boles, W.E. in 3rd Symp. Soc. Avian Paleont. Evol. (ed Peters, D.S.) (Courier Forschungsinstitut Senckenberg. in the press).

8. Godthelp, H., Archer, M., Cifelli, R., Hand, S.J., \& Gilkeson, C.F. Nature 356, 514-516. (1992).

9. Boles, W.E., Godthelp, H., Hand, S.J. \& Archer, M. Alcheringa 18, 71 (1994).
} 